\title{
The risk factors for deep and superficial chest surgical-site infections after coronary artery bypass graft surgery are different
}

\author{
Margaret A. Olsen, MPH, PhD \\ Patricia Lock-Buckley \\ Diane Hopkins, RN, BSN, CIC \\ Louis B. Polish, MD \\ Thoralf M. Sundt, MD* \\ Victoria J. Fraser, MD
}

From the Division of Infectious Diseases and Department of Surgery, Washington University School of Medicine, and the Department of Infection Control, Barnes-Jewish Hospital, St Louis, Mo.

Support for this research provided by Centers for Disease Control Cooperative Prevention Epicenters Agreement UR8/ CCU715087-01.

Received for publication Sept 12, 2001; revisions requested Nov 12, 2001; revisions received Dec 5, 2001; accepted for publication Dec 12, 2001.

Address for reprints: Margaret A. Olsen, MPH, PhD, Campus Box 8051, 660 South Euclid Ave, Division of Infectious Diseases, Washington University School of Medicine, St. Louis, MO 63110-1093 (Email: molsen@im.wustl.edu).

*Current affiliation: Mayo Clinic, Rochester, Minn.

J Thorac Cardiovasc Surg 2002;124:136-45 Copyright ( $(2) 2002$ by The American Association for Thoracic Surgery

$0022-5223 / 2002 \$ 35.00+0 \quad \mathbf{1 2 / 1 / 1 2 2 3 0 6}$

doi: $10.1067 / \mathrm{mtc} .2002 .122306$
Objective: We sought to determine risk factors for deep and superficial chest wound infections after coronary artery bypass graft surgery to develop predictive models.

Methods: We retrospectively analyzed data collected on 1980 consecutive patients undergoing coronary artery bypass surgery at our institution between January 1, 1996, and June 30, 1999, by using the Society of Thoracic Surgery database. Independent risk factors for surgical-site infection were identified with multivariate logistic regression.

Results: There were 37 (1.9\%) deep chest and 46 (2.3\%) superficial chest surgicalsite infections. Obese diabetic patients had a 7.7-fold increased risk of deep chest infections after controlling for intra-aortic balloon pump use (odds ratio, 3.1) and postoperative transfusion (odds ratio, 2.3). Independent risk factors for superficial surgical-site infections included obesity (odds ratio, 3.1), diabetes in persons 65 years of age or older (odds ratio, 2.7), and current smoking (odds ratio, 2.5). Use of antiplatelet drugs was associated with a lower risk of superficial infections (odds ratio, 0.4). Predicted operative mortality as a marker of severity of illness was not clearly predictive of deep or superficial surgical-site infection. Mortality in the year after the operation was increased in patients with deep chest infections compared with that seen in uninfected control subjects (8/37 [21.6\%] vs 114/1612 [7.1\%], $P=$ $.004)$ but not in patients with superficial chest infections (7/47 [15.2\%] vs $114 / 1612$ [7.1\%], $P=.075)$.

Conclusions: Risk factors for deep and superficial chest surgical-site infections after coronary artery bypass surgery differ, suggesting different mechanisms of pathogenesis. Appropriate risk stratification models specific to these important outcomes must be developed.

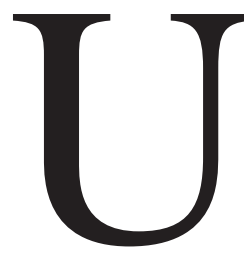
p to $20 \%$ of patients undergoing coronary artery bypass graft (CABG) surgery in the United States have hospital-acquired infections within 30 days of the operation. ${ }^{1}$ Surgical-site infections (SSIs) are among the most morbid and costly. Risk factors for CABG chest SSI consistently identified in multiple studies include obesity, diabetes, female sex, perioperative blood transfusions, reexploration for bleeding, aortic crossclamp time, and use of bilateral internal thoracic artery (ITA) grafts. ${ }^{2-18}$ Advanced age, chronic obstructive pulmonary disease, active smoking, connective tissue disease, reoperation, nasal carriage of Staphylococcus aureus, operative status, postoperative inotropic support, intraaortic balloon pump (IABP) use, postoperative renal failure, and high preoperative 
serum glucose levels ( $\geq 200 \mathrm{mg} / \mathrm{dL}$ ) have been reported as risk factors in some studies. ${ }^{2,3,5,6,8,9,11,12,19-22}$

Risk factors for SSI in patients undergoing CABG must be identified to devise strategies to minimize or eliminate them. Some success has been achieved in this endeavor. Rates of mediastinitis were reduced 2-fold by the use of mechanical clippers rather than razors for hair removal. ${ }^{23}$ Overall SSI rates in patients undergoing elective clean or clean-contaminated operations were reduced more than 2-fold when prophylactic antibiotics were administered no more than 2 hours before incision compared with perioperative administration (0-3 hours after incision). ${ }^{24}$ Zerr and associates $^{25}$ and Furnary and colleagues ${ }^{26}$ reported a reduction in the rate of deep chest SSIs in diabetic patients to the baseline rates observed in their nondiabetic patients by means of implementation of a strict glucose-control policy.

With the ultimate objective of developing a predictive risk model for deep and superficial chest SSI, we retrospectively analyzed our experience with these complications after CABG surgery over a 42 -month period by comparing patients with and without SSIs to control for severity of illness. Data on all our patients undergoing CABG surgery were collected according to the guidelines of the Society of Thoracic Surgeons (STS) national database, which was established for the purpose of risk stratification for mortality after cardiac operations. Thus the variables selected for inclusion in the database are those related to the primary outcome of mortality and include a variety of underlying medical, operative, and postoperative conditions and processes of care. We sought to determine whether these same risk factors predict chest SSI in patients with CABG.

\footnotetext{
Methods

All patients $(\mathrm{n}=1980)$ undergoing CABG surgery at BarnesJewish Hospital between January 1, 1996, and June 30, 1999, were included. Data were collected prospectively. Preoperative demographics, operative details, and postoperative complications were derived from our institutional STS database. All superficial and deep chest SSIs were cross-checked for accuracy by using the hospital's ongoing infection-control database, which is maintained separately from the surgical database by the infection-control department in accordance with Centers for Disease Control and Prevention guidelines. Discrepant results were reconciled with the patient's medical record. Control subjects were excluded from the study only if data for variables found to be important in the multivariate analyses were missing (no infected subjects had missing information).

Only confirmed superficial and deep chest SSIs meeting the National Nosocomial Infections Surveillance criteria and occurring within 30 days of the operation were included in the subsequent analysis. ${ }^{27}$ Deep chest SSIs were defined as involving fascial and muscle layers or organ spaces plus one of the following: (1) purulent drainage from the deep incision or organ space; (2) spontaneous dehiscence of the incision or open exploration by the surgeon in patients with fever (temperature $>38^{\circ} \mathrm{C}$ ), localized
}

pain, or tenderness; (3) abscess or other evidence of deep infection; or (4) diagnosis of deep incisional infection, osteomyelititis, or mediastinitis by a surgeon. Superficial SSIs were defined as involving only skin and subcutaneous tissue of the incision, plus one of the following: (1) purulent drainage from the superficial incision; (2) microorganisms isolated from a culture of fluid or tissue from the superficial incision; (3) pain, tenderness, swelling, redness, or heat in a superficial incision deliberately explored by the surgeon; or (4) diagnosis of superficial incisional infection by the surgeon (assumed when antibiotic therapy was instituted).

Variables analyzed by means of univariate analysis included history of diabetes (including method of treatment), chronic obstructive pulmonary disease, congestive heart failure (including severity and previous myocardial infarction), renal failure, hypertension, hypercholesterolemia, peripheral vascular disease, and cerebrovascular accident (or transient ischemic attack). Baseline characteristics tested included body mass index (BMI; ie, weight in $\mathrm{kg} /\left[\right.$ height in $\mathrm{m}^{2}$ ), smoking history, previous cardiac surgical and nonsurgical interventions, length of hospital stay before the operation, use of inotropic drugs before the operation, number of diseased vessels, and use of various preoperative medications. Operative or postoperative variables included the number and type of blood transfusions received during and after the operation, use of ITA grafts, reexploration for bleeding, use of IABP, operative status, aortic crossclamp time, time on bypass, duration of antibiotic prophylaxis before incision, and mortality after the operation. Active surveillance for mortality in the 30 days after the operation was performed, whereas mortality after 30 days was assessed actively for patients readmitted to our hospital and by means of passive surveillance for patients who did not require readmission (primarily through reporting by physician's office staff).

Because risk factors for SSI might also be risk factors for other types of infections, control patients for all the univariate and multivariate analyses were restricted to those patients with no identified infection within 30 days of the operation. Therefore patients with sepsis, pneumonia, urinary tract infection, or any SSI (chest, radial artery, leg, and IABP site) were excluded from the control population.

Statistical analyses were performed with SPSS 10.0 software (SPSS, Inc, Chicago, Ill). Univariate analyses were performed for all relevant categoric variables by using contingency tables $\left(\chi^{2}\right.$ or Fisher exact tests for variables with small expected cell numbers) and $t$ tests or the Mann-Whitney $U$ test for continuous variables. Multivariate analyses were performed by using logistic regression, in which all variables with a $P$ value of less than .10 in the univariate analyses or that were thought to be related to infection from the literature were included in the initial full models. All 2-way interaction factors involving categoric variables that were deemed relevant were tested in the models after selection of the independent risk factors (main effects) and were included in the final models only if they were significant. ${ }^{28}$ The final models were judged to be a good fit for the data by using the Hosmer and Lemeshow goodness-of-fit test.

\section{Results \\ Prevalence of Deep and Superficial SSIs and Univariate Analyses}

During the 42-month study interval, 1980 patients underwent CABG surgery (isolated or in combination with an- 
TABLE 1. Baseline characteristics of patients who underwent CABG surgery from January 1996 through June 1999

\begin{tabular}{|c|c|c|c|}
\hline Characteristic & $\begin{array}{l}\text { No. }(\%) \text { of patients } \\
\text { with no infection } \\
\quad(n=1612)\end{array}$ & $\begin{array}{l}\text { No. }(\%) \text { of patients with } \\
\text { deep chest infection } \\
(\mathrm{n}=37)\end{array}$ & $\begin{array}{l}\text { No. }(\%) \text { of patients with } \\
\text { superficial chest infection } \\
\qquad(\mathrm{n}=46)\end{array}$ \\
\hline Diabetes (total) & $563(34.9)$ & $24(64.9)$ & $21(45.7)$ \\
\hline Oral therapy & $243(15.2)$ & $11(29.7)$ & $10(21.7)$ \\
\hline Insulin therapy & $236(14.8)$ & $11(29.7)$ & $10(21.7)$ \\
\hline Female sex & $525(32.6)$ & $20(54.1)$ & $21(45.7)$ \\
\hline \multicolumn{4}{|l|}{ Race-ethnicity } \\
\hline White & 1409 (87.4) & $28(75.7)$ & $39(84.8)$ \\
\hline African American & $180(11.2)$ & $9(24.3)$ & $6(13.0)$ \\
\hline Other & $22(1.4)$ & 0 & $1(2.2)$ \\
\hline \multicolumn{4}{|l|}{ Surgical data } \\
\hline CABG only & $1344(83.4)$ & $32(86.5)$ & $38(82.6)$ \\
\hline CABG + valve & $168(10.4)$ & 4 (10.8) & $5(10.9)$ \\
\hline CABG + other* & $77(4.8)$ & $1(2.7)$ & $2(4.3)$ \\
\hline CABG + valve + other & $23(1.4)$ & & $1(2.2)$ \\
\hline Previous CABG surgery & $140(8.7)$ & $2(5.4)$ & $5(10.9)$ \\
\hline \multicolumn{4}{|l|}{ Age $(y)$} \\
\hline$<60$ & $493(30.6)$ & $11(29.7)$ & $20(43.5)$ \\
\hline $60-69$ & $520(32.3)$ & $8(21.6)$ & $13(28.3)$ \\
\hline $70-79$ & $470(29.2)$ & $14(37.8)$ & $8(17.4)$ \\
\hline$>80$ & $129(8.0)$ & $4(10.8)$ & $5(10.9)$ \\
\hline \multicolumn{4}{|l|}{ Obesity: BMI } \\
\hline $30-35$ & $318(19.7)$ & $16(43.2)$ & $13(28.3)$ \\
\hline $35-40$ & $128(7.9)$ & $3(8.1)$ & $7(15.2)$ \\
\hline$>40$ & $47(2.9)$ & $4(10.8)$ & $7(15.2)$ \\
\hline \multicolumn{4}{|l|}{ Smoked cigarettes } \\
\hline Ever & $1090(67.6)$ & $22(59.5)$ & $36(78.3)$ \\
\hline Current smoker & $293(18.2)$ & $4(10.8)$ & $16(34.8)$ \\
\hline \multicolumn{4}{|l|}{$\begin{array}{l}\text { Preexisting comorbidities (other } \\
\text { than diabetes and obesity) }\end{array}$} \\
\hline 0 & $328(20.4)$ & 4 (10.8) & $6(13.3)$ \\
\hline 1 & $732(45.6)$ & $15(40.5)$ & $20(44.4)$ \\
\hline 2 & $363(22.6)$ & $13(35.1)$ & $14(31.1)$ \\
\hline$\geq 3$ & $182(11.4)$ & $5(13.5)$ & $5(11.1)$ \\
\hline $\begin{array}{l}\text { Severe congestive heart failure } \\
\text { (NYHA class III or IV) }\end{array}$ & $406(25.2)$ & $11(29.7)$ & $14(30.4)$ \\
\hline \multicolumn{4}{|l|}{ No. of diseased vessels } \\
\hline None: left main only & $39(2.4)$ & 0 & $2(4.3)$ \\
\hline Single & $216(13.4)$ & $3(8.1)$ & $4(8.7)$ \\
\hline Double & $441(27.4)$ & $11(29.7)$ & $14(30.4)$ \\
\hline Triple & $914(56.7)$ & $23(62.2)$ & $26(56.5)$ \\
\hline \multicolumn{4}{|l|}{ Operative status } \\
\hline Emergency & $101(6.3)$ & $3(8.1)$ & $1(2.2)$ \\
\hline Urgent & $197(12.2)$ & $6(16.2)$ & $3(6.5)$ \\
\hline \multicolumn{4}{|l|}{ No. of ITA grafts used } \\
\hline 0 & $255(15.8)$ & $5(13.5)$ & $6(13.0)$ \\
\hline 1 & $1322(82.2)$ & $29(78.4)$ & $37(80.4)$ \\
\hline 2 & $32(2.0)$ & $3(8.1)$ & $3(6.5)$ \\
\hline \multicolumn{4}{|l|}{ Reoperation for bleeding } \\
\hline Yes & $85(5.3)$ & $2(5.4)$ & 4 (8.7) \\
\hline No & $1527(94.7)$ & $35(94.6)$ & $42(91.3)$ \\
\hline
\end{tabular}

NYHA, New York Heart Association.

${ }^{*}$ Other category includes any additional cardiac procedure performed at the same time as the CABG surgery.

other cardiac procedure). There were 37 (1.9\%) confirmed deep chest and 46 (2.3\%) confirmed superficial chest SSIs. Selected presurgical patient characteristics are shown in Table 1. The ages of patients with deep or superficial chest
SSIs were not significantly different from those of patients without a postsurgical infection (Tables 1 and 2). In contrast, the mean BMI was significantly higher in patients with deep and superficial chest SSIs (Table 2) than in control

138 The Journal of Thoracic and Cardiovascular Surgery • July 2002 
TABLE 2. Univariate analysis of categoric risk factors for deep and superficial chest infections after CABG surgery

\begin{tabular}{|c|c|c|c|c|}
\hline \multirow[b]{2}{*}{ Variable } & \multicolumn{2}{|c|}{ Deep chest infections } & \multicolumn{2}{|c|}{ Superficial chest infections } \\
\hline & OR (95\% Cl) & $P$ value & OR $(95 \% \mathrm{CI})$ & $P$ value \\
\hline Age $\geq 65$ y & $1.19(0.61-2.31)$ & .613 & $0.47(0.26-0.87)$ & .014 \\
\hline Female sex & 2.44 (1.27-4.69) & .006 & $1.74(0.97-3.14)$ & .063 \\
\hline Race (nonwhite) & $2.24(1.04-4.82)$ & .044 & $1.25(0.55-2.84)$ & .590 \\
\hline BMI 25-30 & $1.18(0.39-3.53)$ & .774 & $5.55(1.28-24.14)$ & .022 \\
\hline BMI 30-35 & $4.45(1.61-12.27)$ & .004 & $9.03(2.03-40.31)$ & .004 \\
\hline BMI 35-40 & $2.07(0.49-8.79)$ & .323 & $12.09(2.48-58.89)$ & .002 \\
\hline $\mathrm{BMI}>40$ & $7.52(1.95-28.98)$ & .003 & $32.91(6.65-163.01)$ & $<.001$ \\
\hline $\mathrm{BMI} \geq 30$ & $3.73(1.90-7.31)$ & $<.001$ & $3.23(1.78-5.86)$ & $<.001$ \\
\hline Current smoker of cigarettes & $0.54(0.19-1.54)$ & .244 & $2.39(1.28-4.43)$ & .005 \\
\hline Diabetes (all forms of control) & $3.42(1.73-6.77)$ & $<.001$ & $1.56(0.86-2.81)$ & .138 \\
\hline \multicolumn{5}{|l|}{ Diabetes } \\
\hline Oral control & $3.63(1.61-8.20)$ & .002 & $1.72(0.81-3.62)$ & .157 \\
\hline Insulin control & $3.74(1.65-8.44)$ & .002 & $1.77(0.84-3.73)$ & .136 \\
\hline Hypercholesterolemia & $0.96(0.49-1.88)$ & .909 & $1.86(0.94-3.70)$ & .071 \\
\hline$\geq 2$ previous $\mathrm{Ml}$ & $2.49(1.22-5.11)$ & .010 & $0.56(0.20-1.58)$ & .267 \\
\hline Previous TIA & $3.24(1.32-7.95)$ & .019 & $0.37(0.05-2.73)$ & .513 \\
\hline $\begin{array}{l}\text { Antiplatelet medication before the } \\
\text { operation }\end{array}$ & $1.80(0.70-4.64)$ & .221 & $0.44(0.24-0.80)$ & .006 \\
\hline $\begin{array}{l}\text { Previous nonsurgical cardiac } \\
\text { intervention }\end{array}$ & $1.95(1.00-3.79)$ & .046 & $1.67(0.91-3.08)$ & .094 \\
\hline Previous atherectomy-laser therapy & $0.97(0.23-4.08)$ & 1.000 & $2.54(1.05-6.14)$ & .046 \\
\hline Previous thrombolysis & $1.78(0.54-5.94)$ & .419 & $2.47(0.95-6.42)$ & .070 \\
\hline $\begin{array}{l}\text { IABP inserted during or after CABG } \\
\text { surgery }\end{array}$ & $3.97(1.50-10.55)$ & .014 & $0.57(0.08-4.17)$ & 1.000 \\
\hline Intraoperative cryoprecipitate & $1.76(0.23-13.37)$ & .448 & $4.43(1.29-15.23)$ & .040 \\
\hline Intraoperative Hespan & $2.21(1.03-4.74)$ & .047 & $1.23(0.54-2.79)$ & .617 \\
\hline $\begin{array}{l}\text { Transfusion with } \geq 4 \text { units of RBCs } \\
\text { postoperatively }\end{array}$ & $2.55(1.27-5.15)$ & .007 & $1.67(0.84-3.34)$ & .140 \\
\hline $\begin{array}{l}\text { Transfusion with } \geq 5 \text { units of } \mathrm{RBCs} \\
\text { postoperatively }\end{array}$ & $3.11(1.44-6.71)$ & .007 & $2.35(1.12-4.97)$ & .037 \\
\hline $\begin{array}{l}\text { Transfusion with } \geq 6 \text { units of } \mathrm{RBCs} \\
\text { postoperatively }\end{array}$ & $4.57(2.10-9.93)$ & .001 & $2.13(0.88-5.14)$ & .123 \\
\hline $\begin{array}{l}\text { Transfusion with } \geq 2 \text { units of } \\
\text { platelets postoperatively }\end{array}$ & $4.81(2.21-10.46)$ & $<.001$ & $1.04(0.32-3.42)$ & .763 \\
\hline $\begin{array}{l}\text { Transfusion with } \geq 3 \text { units of } \\
\text { platelets postoperatively }\end{array}$ & 7.29 (3.06-17.39) & $<.001$ & $2.18(0.65-7.26)$ & .180 \\
\hline
\end{tabular}

$M I$, Myocardial infarction; TIA, transient ischemic attack.

subjects. There was a trend toward increasing numbers of comorbidities (other than diabetes and obesity, which were examined separately) in patients with deep chest SSIs $(P=$ $.079, \chi^{2}$ test for linear trend) but not in patients with superficial chest SSIs $(P=.269)$.

Mortality in the first year after the operation was significantly higher in patients with deep chest SSIs than in control subjects $(8 / 37$ [21.6\%] vs $114 / 1612$ [7.1\%]; odds ratio [OR], 3.63; 95\% confidence interval [CI], 1.62-8.11; $P=.004)$, although there was no difference in mortality within 30 days $(P=.438)$. Five of the 8 patients with deep chest SSIs who died within a year of their operation also had sepsis in the month after the operation. Patients with superficial chest SSIs were more likely to die in the first year after the operation than control patients with no infections, although this was only marginally significant (7/46 [15.2\%] vs 114/1612; OR, 2.36; 95\% CI, 1.03-5.39; $P=.075)$. Three of the 7 patients with superficial chest SSIs who died within a year of the operation also were septic postoperatively. Patients with a harvest-site infection in the month after the operation were more likely to have a superficial chest SSI diagnosed than patients without harvest-site infection (6 [7.0\%] patients with both a superficial chest SSI and harvest-site infection of 86 total with harvest-site infection compared with 37 [2.1\%] patients with superficial chest SSI of 1791 without harvest-site infection; $P=.012$, Fisher exact test). In contrast, there was no association between harvest-site infection and deep chest SSI (1/86 [1.2\%] vs 32/1791 [1.8\%], $P=1.00)$.

The microbiology of deep and superficial chest SSI was very similar, although less than one half of the patients with superficial chest SSIs had wound cultures collected. Staph- 
TABLE 3. Univariate analysis of continuous variables as risk factors for deep and superficial chest infections after CABG surgery

\begin{tabular}{|c|c|c|c|c|c|}
\hline Variable & $\begin{array}{l}\text { Patients with deep } \\
\text { chest SSIs }\end{array}$ & $\begin{array}{c}\text { Patients with superficial } \\
\text { chest SSIs }\end{array}$ & $\begin{array}{l}\text { Control subjects with } \\
\text { no postoperative } \\
\text { infection }\end{array}$ & $\begin{array}{c}P \text { value for } \\
\text { deep chest } \\
\text { SSIs* }\end{array}$ & $\begin{array}{l}P \text { value for } \\
\text { superficial } \\
\text { chest SSIs* }\end{array}$ \\
\hline Age (y) & $68(56-76)$ & $62(55-72)$ & $66(57-73)$ & .42 & .128 \\
\hline BMI & $30.4(26.6-33.0)$ & $31.7(26.5-36.3)$ & $27.7(24.6-30.9)$ & .004 & $<.001$ \\
\hline Crossclamp time (min) & $73(55-87)$ & $83(67-108)$ & $85(64-109)$ & .015 & .920 \\
\hline Time on CPB (min) & $126(101-147)$ & $123(102-156)$ & $138(107-168)$ & .075 & .226 \\
\hline Lowest core temperature $\left({ }^{\circ} \mathrm{C}\right)$ & $32(30-33)$ & $32(30-33)$ & $32(31-33)$ & .715 & .377 \\
\hline $\begin{array}{l}\text { Duration of antibiotic prophylaxis } \\
\text { before incision (min) }\end{array}$ & $60(44-80)$ & $65(52-85)$ & $65(50-80)$ & .547 & .792 \\
\hline Length of procedure (min) & $297(251-354)$ & $311(284-373)$ & $305(258-360)$ & .635 & .229 \\
\hline Predicted mortality† & $2.95(1.41-6.06)$ & $1.67(1.09-2.60)$ & $2.02(1.07-3.92)$ & .082 & .415 \\
\hline Chest tube drainage $(\mathrm{mL})$ & $575(425-1100)$ & $655(398-1019)$ & $771(509-1160)$ & .282 & .198 \\
\hline Days on mechanical ventilationł & $0.5(0-0.8)$ & $0.3(0-0.7)$ & $0.4(0.2-0.7)$ & .340 & .247 \\
\hline
\end{tabular}

Values are given as medians (interquartile ranges) where shown.

*Compared with control patients with no infection during the 30 days after the operation (Mann-Whitney $U$ test).

†Percent predicted mortality calculated with the STS software.

$\ddagger$ After the operation.

ylococcus aureus was isolated from $54 \%$ of patients with deep chest SSIs (18/33 patients) and from $41 \%$ of patients with superficial chest SSIs (9/22 patients). Gram-negative bacilli were isolated from approximately one fourth of patients $(8 / 33$ patients with deep SSIs and $5 / 22$ patients with superficial chest SSIs), whereas coagulase-negative staphylococci were isolated slightly more frequently from patients with superficial than those with deep chest SSIs (6/22 vs 4/33 patients).

Results of the univariate analyses for categoric risk factors found to be significantly associated with deep or superficial chest SSIs are shown in Table 2, and the results for continuous variables are shown in Table 3. After correction for testing multiple variables (Bonferroni correction), only obesity (BMI $\geq 30$ ), diabetes, and transfusion of 6 or more units of packed red blood cells (pRBCs) or 2 or more units of platelets postoperatively were significantly associated with deep chest SSI. A dose-response relationship between deep chest infection and the number of units of pRBCs or platelets is evident (Table 2). Obesity was also significantly associated with superficial chest SSI (Tables 2 and 3). A dose-response relationship was apparent between increasing categories of BMI and superficial chest SSI $\left(\chi^{2}\right.$ test for trend $=27.303, P<.001$, Table 2 ). A significant doseresponse relationship increasing categories of BMI and deep chest SSI also existed, although the increase in ORs was not as striking as that seen for superficial chest SSI $\left(\chi^{2}\right.$ test for trend $=13.394, P<.001$, Table 2).

\section{Predicted Risk of Mortality and Prevalence of Deep and Superficial SSI}

Interestingly, almost no other variables representing underlying severity of illness other than diabetes and obesity were significantly associated with deep or superficial chest SSI by means of univariate analysis. Rates of infection were compared with the predicted risk of mortality computed with the STS software to confirm this. ${ }^{29}$ The rates of superficial chest SSI showed no correlation with the predicted risk of mortality (Figure 1), irrespective of whether the predicted risk categories were split into quartiles, quintiles, or traditional risk groups (Figure 1). The correlation of deep chest SSI with predicted risk of mortality was dependent on the way in which the predicted risk of mortality was categorized. If predicted risk was categorized by quintiles or more traditional risk groups (Figure 1), there was a significant trend toward increasing risk of deep chest SSI with increased predicted mortality $(P=.035$ for quintiles and $P=.049$ for grouping shown in Figure 1, $\chi^{2}$ test for trend). If, however, predicted risk was categorized as quartiles, the trend was no longer statistically significant $\left(P=.129, \chi^{2}\right.$ test for trend). In contrast, significant linear trends of increasing risk of SSI with increasing predicted risk of mortality were observed for all the systemic infections recorded in the STS database, no matter how predicted risk was categorized..$^{30}$

\section{Predictors of Deep SSI From the Multivariate Analyses}

The results of the multivariate analyses to identify independent risk factors associated with deep chest SSI are shown in Table 4. Obesity, diabetes, transfusion of 4 or more units of pRBCs postoperatively, and IABP insertion during or after the operation were all independent risk factors for deep chest SSI. Additional multivariate models were created to assess interactions between variables. In Table 5 the interaction of obesity and diabetes was compared for deep and superficial infection after controlling for respective independent risk fac- 


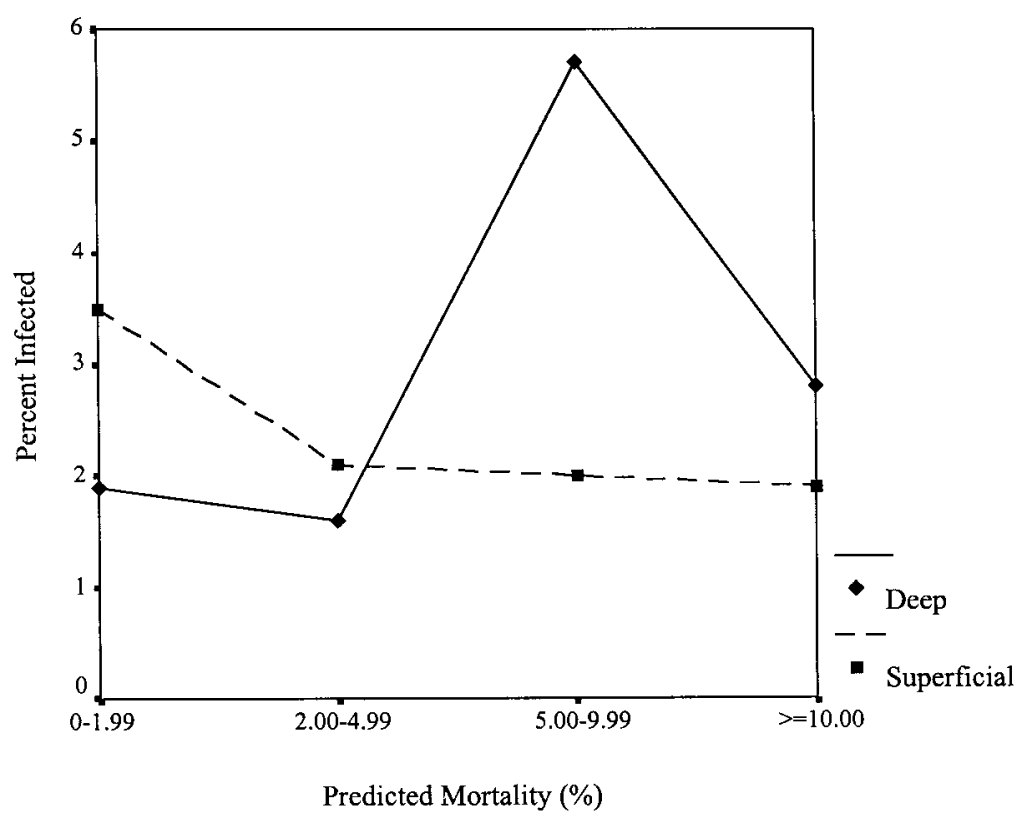

Figure 1. Percentage of patients with deep or superficial chest SSIs according to preoperative predicted mortality. The percentage of predicted operative mortality, calculated by using the STS software, was categorized into 4 groups: $0 \%$ to $1.99 \% ; 2 \%$ to $4.99 \%$; $5 \%$ to $9.99 \%$; and $10 \%$ and greater. The percentage of patients with deep or superficial chest SSIs was determined within each category of predicted mortality.

TABLE 4. Multivariate analysis of independent risk factors for deep and superficial chest SSI

\begin{tabular}{|c|c|c|c|c|}
\hline \multirow[b]{2}{*}{ Risk factor } & \multicolumn{2}{|c|}{ Deep chest infections } & \multicolumn{2}{|c|}{ Superficial chest infections } \\
\hline & OR (95\% CI) & $P$ value & OR (95\% CI) & $P$ value \\
\hline Obesity (BMI $\geq 30$ ) & $3.36(1.69-6.67)$ & .001 & $3.50(1.92-6.40)$ & $<.001$ \\
\hline Diabetes & $2.85(1.42-5.70)$ & .003 & & \\
\hline$\geq 4$ units pRBCs postoperatively & $2.39(1.13-5.06)$ & .022 & & \\
\hline IABP & $2.81(0.98-8.03)$ & .054 & & \\
\hline Current smoking & & & $2.68(1.43-5.03)$ & .002 \\
\hline Antiplatelets & & & $0.39(0.21-0.73)$ & .003 \\
\hline
\end{tabular}

tors. Compared with control subjects, obese diabetic patients were at greatest risk of both superficial and deep chest SSI. Obese patients who did not have diabetes were at increased risk of superficial, but not deep, chest SSI. Nonobese diabetic patients were not at increased risk for either. Thus the relative contributions of obesity and diabetes to deep and superficial SSI appear different, with obesity alone being the primary risk factor for superficial SSI, whereas for deep SSI, the interaction of obesity and diabetes confers the greatest risk.

A second multivariate model for deep chest SSI includes the interaction of postoperative transfusion and obesity (Table 6). Among nonobese (BMI $\leq 30)$ patients, deep chest SSI was more likely to occur in those who received 4 or more units of pRBCs postoperatively than among those who did not. This relationship was also apparent if 2 or more units of platelets was used to define increased rates of transfusions postoperatively (adjusted OR for deep chest SSI in nonobese persons who received 2 or more units of platelets postoperatively $=14.2 ; 95 \% \mathrm{CI}, 4.6-44.0 ; P<$ $.001)$. In contrast, obese individuals were just as likely to have a deep chest SSI, irrespective of whether they required transfusions (risk of deep chest SSI in obese patients who received $\geq 4$ units of $\mathrm{pRBC}$ vs obese patients who received $<4$ units of pRBCs, $P=.552$ ). The lack of a relationship between increased rates of transfusions and deep chest SSI in obese individuals was confirmed when transfusion was defined as receipt of 2 or more units of platelets postoperatively (comparison of deep chest SSI in obese patients who received $\geq 2$ units of platelets postoperatively and obese patients receiving $<2$ units of platelets, $P=1.0$ ). 
TABLE 5. Risk of superficial and deep chest infections according to coexisting obesity, diabetes, or both*

\begin{tabular}{|c|c|c|c|c|c|c|}
\hline \multirow[b]{2}{*}{ Category } & \multicolumn{3}{|c|}{ Deep chest infections } & \multicolumn{3}{|c|}{ Superficial chest infections } \\
\hline & $\begin{array}{l}\text { No. of infected patients/total in } \\
\text { category }(\%)\end{array}$ & $\begin{array}{c}\text { OR† } \\
(95 \% \mathrm{CI})\end{array}$ & $P$ value & $\begin{array}{l}\text { No. of infected patients/total in } \\
\text { category }(\%)\end{array}$ & $\begin{array}{c}\text { OR } ¥ \\
(95 \% \mathrm{CI})\end{array}$ & $P$ value \\
\hline Neither diabetic nor obese & $9 / 778(1.2)$ & 1.0 & & $11 / 780(1.4)$ & 1.0 & \\
\hline Diabetic only & $5 / 351(1.4)$ & $1.2(0.4-3.6)$ & .761 & $8 / 354(2.3)$ & $1.7(0.7-4.4)$ & .238 \\
\hline Obese only & $4 / 277(1.4)$ & $1.3(0.4-4.2)$ & .682 & $14 / 287(4.9)$ & $3.9(1.7-8.8)$ & .001 \\
\hline Both diabetic and obese & 19/237 (8.0) & $7.7(3.4-17.4)$ & $<.001$ & $13 / 231(5.6)$ & $4.7(2.1-10.9)$ & .001 \\
\hline
\end{tabular}

${ }^{*}$ Compared with 1607 control patients with no infections during the 30-day postoperative period.

TOR for deep chest infections after controlling for 4 or more units of pRBCs transfused postoperatively (adjusted $0 \mathrm{R}, 2.3 ; 95 \% \mathrm{Cl}, 1.1-5.0$ ) and IABP placed during or after the operation (adjusted $\mathrm{OR}, 3.1 ; 95 \% \mathrm{Cl}, 1.1-8.9$ ).

$\ddagger 0 R$ for superficial chest infections after controlling for current smoking (adjusted $\mathrm{OR}, 2.8 ; 95 \% \mathrm{Cl}, 1.5-5.2$ ) and antiplatelet use before the operation (adjusted OR, 0.4; 95\% $\mathrm{Cl}, 0.2-0.7$ ).

TABLE 6. Postoperative transfusion is a risk factor for deep chest infections in nonobese patients but not in obese patients

\begin{tabular}{lcrrr}
\hline Obesity & $\begin{array}{c}\mathbf{Z} \text { 4 units of pRBCs } \\
\text { postoperatively }\end{array}$ & $\begin{array}{c}\text { No. of infected } \\
\text { patients/total } \\
\text { in category (\%) }\end{array}$ & $\begin{array}{c}\text { ORs* } \\
(\mathbf{9 5 \%} \% \mathbf{C l})\end{array}$ & $\boldsymbol{P}$ value \\
\hline No & No & $6 / 939(0.6)$ & 1.0 & \\
No & Yes & $8 / 194(4.1)$ & $5.9(2.0-17.7)$ & .001 \\
Yes & No & $19 / 443(4.3)$ & $6.0(2.4-15.3)$ & $<.001$ \\
Yes & Yes & $4 / 73(5.5)$ & $6.5(1.7-24.2)$ & .006
\end{tabular}

${ }^{*} \mathrm{ORs}$ adjusted for diabetes (adjusted $\mathrm{OR}, 2.9 ; 95 \% \mathrm{Cl}, 1.4-5.8$ ) and IABP placed during or after the operation (adjusted $\mathrm{OR}, 2.8 ; 95 \% \mathrm{Cl}, 1.0-8.0$ ).

\section{Predictors of Superficial Chest SSI in the Multivariate Analysis}

The multivariate model for superficial chest SSI included the independent risk factors of obesity, current smoking, and use of antiplatelet drugs before the operation (Table 4). In a separate model analyzing the interaction between age ( $<65$ years) and diabetes, increased risk of superficial chest SSI was limited to younger diabetic patients, with an OR of 2.7 compared with younger patients without diabetes (after adjusting for other risk factors in the multivariate model, Table 7). Older diabetic patients were not at increased risk of superficial chest SSI and were also less likely than younger diabetic patients to be obese (31\% vs $49 \%$; $P<$ $.001, \chi^{2}$ test) and less likely than younger diabetic patients to be receiving insulin therapy ( $38 \%$ vs $47 \% ; P=.028, \chi^{2}$ test). The increased risk of superficial chest SSI in younger diabetic patients remained significant after adjusting for BMI as a continuous variable, suggesting that some factor other than obesity was responsible for this increased risk in these patients.

\section{Adjusted Risk of Infection by Surgeon}

The results from the multivariate models were then used to examine the association of individual staff surgeons and residents with deep and superficial chest SSIs. The percent-
TABLE 7. Younger, but not older, diabetic patients have increased risk for superficial chest infection

\begin{tabular}{lcccc}
\hline Diabetes & Age $\geq \mathbf{6 5}$ y & $\begin{array}{c}\text { No. of infected } \\
\text { patients/total in } \\
\text { category (\%) }\end{array}$ & $\begin{array}{c}\text { ORs* } \\
(\mathbf{9 5 \%} \% \mathbf{C l})\end{array}$ & $\boldsymbol{P}$ value \\
\hline No & No & $11 / 474(2.3)$ & 1.0 & \\
No & Yes & $14 / 593(2.4)$ & $1.4(0.6-3.3)$ & .413 \\
Yes & No & $18 / 273(6.6)$ & $2.7(1.2-6.0)$ & .013 \\
Yes & Yes & $3 / 312(1.0)$ & $0.5(0.1-2.0)$ & .354 \\
\hline
\end{tabular}

*ORs adjusted for obesity (BMI $\geq 30$; adjusted $\mathrm{OR}, 3.1 ; 95 \% \mathrm{Cl}, 1.7-5.8$ ), current smoking (adjusted $\mathrm{OR}, 2.5 ; 95 \% \mathrm{Cl}, 1.3-4.9$ ), and antiplatelet use before the operation (adjusted $\mathrm{OR}, 0.4 ; 95 \% \mathrm{Cl}, 0.2-0.8$ ).

age of patients with superficial chest SSIs varied from $0 \%$ to $7.7 \%$ for the 17 individual residents with a sufficient number of procedures to analyze and from $0 \%$ to $12.5 \%$ for 12 individual attending surgeons. For deep chest SSI, rates ranged from $0 \%$ to $7.1 \%$ for individual residents and from $0 \%$ to $4.7 \%$ for individual attending surgeons. We chose to analyze the odds of SSI according to resident by creating a categoric variable, including all individual residents whose rate of infection was above the mean rate $(2.3 \%$ for superficial infection and $1.9 \%$ for deep chest infection) and using all individuals at or below the mean as the single reference category. The ORs for superficial and deep SSIs were calculated for the residents and attending surgeons after adjusting for the independent risk factors identified in the multivariate analyses. Six residents had significantly elevated ORs for superficial chest SSIs by using this criteria (OR range, 3.8-10.6), and 3 of these same residents had significantly elevated ORs for deep chest SSIs (ORs of 4.5, 5.7, and 13.5, respectively). The same analyses performed for attending surgeons identified 3 surgeons with significantly elevated ORs for superficial chest SSIs (ORs of 2.2, 3.6, and 9.7, respectively), and one surgeon with a significantly elevated OR for deep chest SSIs (OR, 4.6).

During the 42-month time period of this study, one outbreak of 6 deep chest SSIs associated with one individual 
resident occurred (OR, 13.5). The dates of operation for the outbreak cases were clustered in a 25-day period, and the infections were associated with a variety of different bacteria (no common organism). After exclusion of the 6 outbreak cases from analysis, the one surgeon identified above no longer had an elevated OR for deep chest SSI. In contrast, no outbreaks of superficial chest SSI were identified, and the same 3 surgeons had significantly elevated ORs for superficial chest SSI when the ORs of superficial SSI were calculated for surgeons after controlling for residents in the multivariate model.

\section{Discussion}

This analysis of risk factors for deep and superficial chest SSI after CABG surgery indicates that the risk factors for the 2 types of SSI differ. Increased risk of deep chest SSI was associated with a combination of obesity and diabetes, whereas increased risk of superficial chest SSI was associated primarily with obesity and, to a much lesser extent, diabetes. The placement of an IABP during or after the operation and postoperative transfusions were independent risk factors for deep chest SSI, whereas current smoking was a risk factor specifically for superficial chest infections, and antiplatelet use was protective of superficial chest SSI.

The risk of superficial chest SSI was significantly increased in patients with a harvest-site infection in the month after the operation in comparison with patients without a harvest-site infection. The majority of the harvest SSIs in our patient population were superficial infections, and thus the increased risk of only superficial chest, but not deep chest, SSI might be due to common risk factors for superficial infection..$^{31}$ Mortality was significantly increased in patients with deep chest SSIs in the year after CABG surgery in comparison with that seen in uninfected control subjects. Although our assessment of mortality beyond the first month after the operation relied primarily on passive reporting, the $22 \%$ mortality rate observed in our patients with deep chest SSIs is consistent with that reported previously in other studies. ${ }^{11,32,33}$ Interestingly, we also found an increased risk of 1-year mortality in patients with superficial chest SSIs compared with that seen in uninfected control subjects, attesting to the clinical importance of these outcomes.

\section{Association of Deep Chest SSI With Predicted Mortality}

Consistent with the lack of association between superficial chest SSI and number of comorbidities and the results of the multivariate analysis, we did not observe an association between the predicted risk of mortality and the prevalence of superficial chest SSI. The association between predicted risk of mortality and deep chest SSI was equivocal and depended on the categorization of the predicted risk. In contrast, we have found that the prevalences of sepsis and pneumonia in the month after CABG surgery are linearly related to increasing predicted mortality. ${ }^{30}$ Hattler and colleagues ${ }^{34}$ have previously reported significantly increased risks of mediastinitis and septicemia in patients with a $30 \%$ predicted risk of mortality or higher compared with that seen in patients with the lowest risk of mortality. This difference might have been due to the small number of cases during our study period. Clarification of this result will likely require a multi-institutional analysis of a larger number of patients.

\section{Increased Risk of Deep Chest SSI in Obese Diabetic Patients}

The increased risk of deep chest SSI in obese, but not in nonobese, diabetic patients might be due to poor glucose control. Increased risk of deep chest SSI after CABG surgery has been demonstrated in diabetic patients with preoperative serum glucose levels exceeding $200 \mathrm{mg} / \mathrm{dL} .{ }^{22}$ Diabetic patients with serum glucose levels of less than 200 $\mathrm{mg} / \mathrm{dL}$ were not at increased risk. Furthermore, implementation of a strict glucose-control regimen has been shown to reduce deep chest SSIs in diabetic patients to the baseline rate for patients without diabetes. ${ }^{25,26}$ Unfortunately, we do not have data on perioperative glucose levels for the study patients; however, obese diabetic patients are more likely to have high serum glucose levels than nonobese diabetic patients. ${ }^{35}$

\section{Transfusion as a Risk Factor for Deep Chest SSI}

In both the stratified and multivariate analyses, nonobese patients receiving large numbers of transfusions were at increased risk of deep, but not superficial, chest SSI. This increased risk might be attributed to immunosuppressive effects of blood transfusion, the presence of a hematoma to act as a culture medium for bacterial growth, or the possibility that bleeding is indicative of compromised wound closure. Receipt of blood products after CABG surgery has previously been associated with prolonged hospital stay and an increased incidence of sepsis and pneumonia. ${ }^{18,36}$ Other investigators have suggested that white blood cells contaminating $\mathrm{pRBC}$ and platelet units might act as immunomodulators. ${ }^{18}$ Interestingly, obese patients requiring transfusion were not at increased risk of deep chest infection in this study. This could be a statistical artifact given the small number of obese patients with deep chest SSIs who required multiple transfusions.

\section{Additional Risk Factors for Deep and Superficial Chest SSI}

Active smoking was an independent risk factor for superficial chest SSI, possibly because of impaired cutaneous circulation. Conversely, use of antiplatelet medication before the operation was associated with a decreased risk of 
superficial chest infections, but not deep chest infections, possibly as a result of improved circulation. Neither of these factors was associated with deep chest SSI. Placement of an IABP during or after the operation was associated with an increased risk of deep chest SSI, possibly reflecting a relationship between tissue perfusion and infection. Because the number of patients in our study who required an IABP was small (66 patients), this finding requires confirmation in larger studies.

\section{Analysis of Surgeon and Resident Rates of Infection After Risk Adjustment}

We used the results of our multivariate models to control for independent risk factors in analyzing infection rates for surgical staff. Several residents and staff surgeons had adjusted rates of superficial chest infections significantly higher than those of their peers, which was not a surprising finding given the large number of individual residents and surgeons involved. What was of interest, however, was that 3 residents were found to have significantly higher rates of both superficial and deep chest SSI than their peers. This suggests that this type of risk-adjusted comparison could be used on an ongoing basis for identification of surgical practices associated with higher than expected rates of infection and could be the basis for education and intervention.

\section{Study Limitations and Strengths}

As in most previous reports, the principle limitation of this study is the small numbers of superficial and deep chest SSIs. Resolution of this will likely require a multi-institutional approach because of the low prevalence of these infections in most centers. Despite this, the numbers of superficial and deep SSIs in this study are still larger than those in most other published reports. Furthermore, our study benefits from the rigor of the data set, with confirmation of SSI by using National Nosocomial Infections Surveillance criteria to verify the identification of deep and superficial infections. The STS database includes a large quantity of information on potential risk factors, although admittedly some potential predictor variables are not available, such as oxygen saturation. Our database does, however, include information concerning the number of units of transfused blood products, duration of antibiotic prophylaxis, and other data added at the request of our infectioncontrol program. Because our database included information on a variety of other infectious outcomes, we were also able to exclude patients with other infections as control subjects.

Our multivariate analysis of risk factors for deep and superficial chest SSIs included all potentially relevant 2-way interaction factors. We were interested in the interaction of obesity and other factors in this patient population to determine whether there are unique groups of patients undergoing $\mathrm{CABG}$ who are at increased risk of infection because of their combination of different risk factors. We identified obese diabetic and nonobese individuals with excessive bleeding postoperatively as being at higher risk of deep chest infections. There was no interaction between diabetes and receipt of bilateral ITA grafts because the number of patients who received bilateral ITA grafts during the interval of this study was very small. To our knowledge, only 2 previous studies ${ }^{22,37}$ have included an analysis of interactions between variables to determine whether particular subsets of patients are at increased risk of infection, although only one of these studies analyzed specifically the risk of deep chest SSI. ${ }^{22}$

The major strength of this study was the construction of separate models to discriminate between risk factors for deep versus superficial chest SSI. Of the many previous studies of chest wound infections in patients undergoing CABG, most have analyzed risk factors for superficial and deep chest SSIs together (ie, reported risks for chest infections ${ }^{2,3,5,7,14}$ ) or have analyzed deep chest infections or mediastinitis only. ${ }^{6,11,16,17,19,22}$ In addition, some studies have pooled the analyses to include patients with any SSI, obscuring the delineation of risk factors specific to chest or harvest-site infections. ${ }^{9,12,13,15,37}$ Our analysis of deep and superficial chest SSI separately has allowed for the discrimination of risk factors unique to each infection, emphasizing the difference in the 2 types of infection.

\section{Relevance to Infection Control}

The goal of this analysis was to use the knowledge of risk factors to develop strategies to reduce the incidence of SSI in patients undergoing CABG. The most obvious strategy to reduce the incidence of deep chest SSI supported by the findings of this study is the implementation of a diabetic protocol $^{25,26}$ to maintain adequate serum glucose levels in obese diabetic patients. Another potential method to reduce the risk of deep chest SSI is the use of antibiotic prophylaxis in patients at increased risk because of transfusion with very large amounts of blood products postoperatively. Prophylaxis of multiply transfused patients cannot be recommended on the basis of this study alone because the time after the operation that transfusions were given is not known. A further method to reduce the risk of deep chest SSI in multiply transfused patients involves the use of white blood cell-depleted blood products, although it is not clear from the results of randomized clinical trials that this reduces the risk of SSI. ${ }^{18}$ Development of interventions to reduce the risk of superficial chest SSI are more difficult to envision because the risk factors for these infections cannot be directly modified by physicians or infection-control personnel. Clearly more work needs to be done in the area of infection control to develop new interventions to reduce the risk of SSI in patients undergoing CABG surgery. 


\section{Summary}

Deep chest SSI continues to be a serious complication of CABG surgery, carrying with it the prospect of substantial morbidity, increased mortality, and high costs. Superficial chest SSI results in additional, albeit less profound, morbidity and increased costs. We have demonstrated different independent risk factors for the 2 infections, suggesting different mechanisms of pathogenesis. We have also identified specific combinations of risk factors that place patients at particularly high risk. These results further suggest that risk stratification can be used to adjust rates of infection associated with individual surgeons for the purpose of quality-improvement programs.

We thank the members of the Division of Cardiothoracic Surgery at Washington University who performed the operative procedures included in this study: Hendrick B. Barner; James L. Cox; T. Bruce Ferguson, Jr; William A. Gay, Jr; Charles Huddleston; Scott Johnson; Eric Mendeloff; Marc R. Moon; Kevin Murray; Michel K. Pasque; and Michael Rosenbloom. We also acknowledge the exceptional work of Tina Burmeister in managing our institutional STS database.

\section{References}

1. Kollef MH, Sharpless L, Vlasnik J, Pasque C, Murphy D, Fraser VJ. The impact of nosocomial infections on patient outcomes following cardiac surgery. Chest. 1997;112:666-75.

2. Nagachinta T, Stephens M, Reitz B, Polk BF. Risk factors for surgicalwound infection following cardiac surgery. J Infect Dis. 1987;156:967-73.

3. Hazelrigg SR, Wellons HA Jr, Schneider JA, Kolm P. Wound complications after median sternotomy. Relationship to internal mammary grafting. J Thorac Cardiovasc Surg. 1989;98:1096-9.

4. He GW, Ryan WH, Acuff TE, et al. Risk factors for operative mortality and chest wound infection in bilateral internal mammary artery grafting. J Thorac Cardiovasc Surg. 1994;107:196-202.

5. Blanchard A, Hurni M, Ruchat P, Stumpe F, Fischer A, Sadeghi H. Incidence of deep and superficial chest infection after open heart surgery. A ten years retrospective study from 1981 to 1991. Eur J Cardiothorac Surg. 1995;9:153-7.

6. The Parisian Mediastinitis Study Group. Risk factors for deep chest wound infection after sternotomy: a prospective, multicenter study. J Thorac Cardiovasc Surg. 1996;111:1200-7.

7. Zacharias A, Habib RH. Factors predisposing to median sternotomy complications. Deep vs superficial infection. Chest. 1996;110:1173-8.

8. Birkmeyer NJ, Charlesworth DC, Hernandez F, et al. Obesity and risk of adverse outcomes associated with coronary artery bypass surgery. Northern New England Cardiovascular Disease Study Group. Circulation. 1998;97:1689-94.

9. Vuorisalo S, Haukipuro K, Pokela R, Syrjälä H. Risk features for surgical-site infections in coronary artery bypass surgery. Infect Control Hosp Epidemiol. 1998;19:240-7.

10. Engleman DT, Adam DH, Byrne JG, et al. Impact of body mass index and albumin on morbidity and mortality after cardiac surgery. $J$ Thorac Cardiovasc Surg. 1999;118:866-73.

11. Hollenbeak CS, Murphy DM, Koenig S, Woodward RS, Dunagan WC, Fraser VJ. The clinical and economic impact of deep chest surgical site infections following coronary artery bypass graft surgery. Chest. 2000;118:397-402.

12. Jakob HG, Borneff-Lipp M, Bach A, et al. The endogenous pathway is a major route for deep chest wound infection. Eur J Cardiothorac Surg. 2000; 17:154-60.

13. Spelman DW, Russo P, Harrington G, et al. Risk factors for surgical wound infection and bacteraemia following coronary artery bypass surgery. Aust N Z J Surg. 2000;70:47-51.

14. Grossi EA, Esposito R, Harris LJ, et al. Chest wound infections and use of internal mammary artery grafts. J Thorac Cardiovasc Surg. 1991;102:342-6.
15. Slaughter MS, Olson MM, Lee JT Jr, Ward HB. A fifteen-year wound surveillance study after coronary artery bypass. Ann Thorac Surg. 1993;56:1063-8.

16. Ståhle E, Tammelin A, Bergström R, Hambreus A, Nyström SO, Hansson HE. Sternal wound complications-incidence, microbiology and risk factors. Eur J Cardiothorac Surg. 1997;11:1146-53.

17. Borger MA, Rao V, Weisel RD, et al. Deep chest wound infection: risk factors and outcomes. Ann Thorac Surg. 1998;65:1050-6.

18. Vamvakas EC, Carven JH. RBC transfusion and postoperative length of stay in the hospital or the intensive care unit among patients undergoing coronary artery bypass graft surgery: the effects of confounding factors. Transfusion. 2000;40:832-9.

19. Newman LS, Szczukowski LC, Bain RP, Perlino CA. Suppurative mediastinitis after open heart surgery. Chest. 1988;94:546-53.

20. Demmy TL, Park SB, Liebler GA, et al. Recent experience with major chest wound complications. Ann Thorac Surg. 1990;49:458-62.

21. Kluytmans JAJW, Mouton JW, Izerman EPF, et al. Nasal carriage of Staphylococcus aureus as a major risk factor for wound infections after cardiac surgery. J Infect Dis. 1995;171:216-9.

22. Trick WE, Scheckler WE, Tokars JI, et al. Modifiable risk factors associated with deep chest site infection after coronary artery bypass grafting. J Thorac Cardiovasc Surg. 2000;119:108-14.

23. Ko W, Lazenby WD, Zelano JA, Isom OW, Krieger KH. Effects of shaving methods and intraoperative irrigation on suppurative mediastinitis after bypass operations. Ann Thorac Surg. 1992;53:301-5.

24. Classen DC, Evans RS, Pestotnik SL, Horn SD, Menlove RL, Burke JP. The timing of prophylactic administrations of antibiotics and the risk of surgical-wound infection. N Engl J Med. 1992;326:281-6.

25. Zerr KJ, Furnary AP, Grunkemeier GL, Bookin S, Kanhere V, Starr A. Glucose control lowers the risk of wound infection in diabetics after open heart operations. Ann Thorac Surg. 1997;63:356-61.

26. Furnary AP, Zerr KJ, Grunkemeier GL, Starr A. Continuous intravenous insulin infusion reduces the incidence of deep chest wound infection in diabetic patients after cardiac surgical procedures. Ann Thorac Surg. 1999;67:352-60.

27. Horan TC, Gaynes RP, Martone WJ, Jarvis WR, Emori TG. CDC definitions of nosocomial surgical site infections, 1992: a modification of CDC definitions of surgical wound infections. Infect Control Hosp Epidemiol. 1992;13:606-8.

28. Hosmer DW, Lemeshow S. Applied logistic regression. New York: John Wiley \& Sons; 2000.

29. Shroyer AL, Plomondon ME, Grover FL, Edwards FH. The 1996 coronary artery bypass risk model: the Society of Thoracic Surgeons Adult Cardiac National Database. Ann Thorac Surg. 1999;67:1205-8.

30. Olsen MA, Fraser VJ, Polish LB, Sundt TM. Severity of illness predicts risk of systemic infection following coronary artery bypass surgery. Presented at the American Heart Association Scientific Sessions 2001 [abstract 100325]; 2001 Nov 11-14; Anaheim, Calif.

31. Olsen MA, Polish LB, Sundt TM, Fraser VJ. Risk of leg surgical site infection following coronary artery bypass. Presented at the 39th Annual Meeting of the Infectious Diseases Society of America [abstract 221]; 2001 Oct 25-28; San Francisco, Calif.

32. Milano CA, Kesler K, Archibald N, Sexton DJ, Jones RH. Mediastinitis after coronary artery bypass graft surgery. Circulation. 1995;92:2245-51.

33. Braxton JH, Marrin CAS, McGrath PD, et al. Mediastinitis and long-term survival after coronary artery bypass surgery. Ann Thorac Surg. 2000;70:2004-7.

34. Hattler BG, Madia C, Johnson C, et al. Risk stratification using the Society of Thoracic Surgeons program. Ann Thorac Surg. 1994;58: 1348-52.

35. Modan M, Karasik A, Halkin H, et al. Effect of past and concurrent body mass index on prevalence of glucose intolerance and type 2 (non-insulin-dependent) diabetes and on insulin response. Diabetologia. 1986;29:82-9.

36. Vamvakas EC, Carven JH. Transfusion and postoperative pneumonia in coronary artery bypass graft surgery: effect of the length of storage of transfused red cells. Transfusion. 1999;39:701-10.

37. Harbarth S, Samore MH, Lichtenberg D, Carmeli Y. Prolonged antibiotic prophylaxis after cardiovascular surgery and its effect on surgical site infections and antimicrobial resistance. Circulation. 2000; 101:2916-21. 